2018-11-05

\title{
Predicting Performance - A Dynamic Capability View
}

Nudurupati, S

http://hdl.handle.net/10026.1/11574

10.1108/IJOPM-10-2016-0601

International Journal of Operations and Production Management

Emerald

All content in PEARL is protected by copyright law. Author manuscripts are made available in accordance with publisher policies. Please cite only the published version using the details provided on the item record or document. In the absence of an open licence (e.g. Creative Commons), permissions for further reuse of content should be sought from the publisher or author. 


\section{Predicting Performance - A Dynamic Capability View}

\section{Abstract}

\section{Purpose}

Production planning and resource allocation are ongoing issues that organisations face on a day-to-day basis. The study addresses these issues by developing a dynamic performance measurement system (DPMS) to effectively re-deploy manufacturing resources, thus enhancing the decision-making process in optimising performance output. The study also explores the development of dynamic capabilities through exploitation of the organisational tacit knowledge.

\section{Design/methodology/approach}

The study was conducted using 6-stage action research for developing DPMS with real-time control of independent variables on the production lines to study the impact. The DPMS was developed using a hybrid approach of discrete event simulation (DES) and system dynamics (SD) by using the historical as well as live data from the action case organisation.

\section{Findings}

Through the development of DPMS and by combining the explicit and tacit knowledge, this study demonstrated an understanding of using cause and effect analysis in manufacturing systems to predict performance. Such a DPMS creates agility in decision making and significantly enhances the decision-making process under uncertainty. The research also explored how the resources can be developed and maintained into dynamic capabilities to sustain competitive advantage. 


\section{Research limitations/implications}

The present study provides a starting-point for further research in other manufacturing organisations to generalise findings.

\section{Originality/value}

The originality of the DPMS model comes from the approach used to build the cause and effect analysis by exploiting the tacit knowledge and making it dynamic by adding modelling capabilities. Originality also comes from the hybrid approach used in developing the DPMS.

Keywords: Predictive Performance, Dynamic Performance Measurement System, System Dynamics, Discrete Event Simulation, Dynamic Capabilities, Cause and Effect Analysis

Paper Type: Research Paper 


\section{Introduction}

To fully understand the root causes leading to excellent or poor performance in manufacturing has been a debate in both operations management and performance measurement literature (Bititci and Nudurupati, 2002; Suwingnjo et al., 2000). Exploring the relationships between various input factors or resources affecting manufacturing performance is important for operations strategy and operations decision-making (Silvestro and Lustrato, 2014; Tan and Platts 2005; 2009). Measures such as Overall Equipment Effectiveness (OEE), utilization and throughput are predominantly used to improve manufacturing productivity (Huang et al., 2003). The vast majority of decision-making tools such as APP (Aggregate Production Planning) tools were developed and tested using mainly explicit knowledge (Jamalnia and Feili, 2011). While there is abundant research on how to measure them (Liu et al., 2004; Ahmed and Sahinidis, 1998; Silver et al., 1998), there is comparatively little research on identifying the inputs and resources (root causes) that influence them (Jeong and Phillips, 2001). These bundles of resources can constitute a basis for competitive advantage and for the development of dynamic capabilities (Rothaermel, 2013; Teece et al., 1997).

While the purpose of performance measurement is to measure the effectiveness and efficiency of actions (Neely et al., 1995), the majority of information is based on static and explicit knowledge with emphasis on tangible assets (Neely, 2005). Given the challenges of fast changing business trends (Bititci et al., 2012) and the advent of information technology (Harrington et al., 2011; Harrison and van Hoek, 2011), organisations need to be fast in making decisions, flexible in planning their resources and proactive in addressing the changing strategies to retain competitive advantage going beyond the exploitation of the measurable operational knowledge (Neely, 2005; Melnyk et al., 2014). While Neely (2005) argues the need for dynamic performance measurement systems, Melnyk et al (2014) confirm the lack of such models to support businesses in implementing and monitoring their strategies. Neely (2005) also argues the need for measuring both tangible and intangible assets thus drawing the focus 
on capturing both explicit and tacit knowledge (Anand et al., 2009) in understanding the performance of the business. Improved understanding - particularly as production conditions change - is vital to measure performance and to manage resources. Few researchers have explored the usefulness of modelling approaches that could complement performance measurement systems by identifying and predicting future performance thus making them more dynamic (Warren, 2008; Santos et al., 2002; Bititci, 1996)

The current focus of trends in modelling manufacturing performance literature is on discreteevent simulation (DES) (Negahban and Smith, 2014; Chopra and Meindl, 2007). To overcome some of the DES limitations and to capture the dynamics of the manufacturing processes, Santos et al (2002) attempted to develop performance measurement systems using system dynamics (SD). This approach models the relationships between possible causes and effects and develops dynamic decision support tools (Venkateswaran and Son, 2007, Rabelo et al., 2005). There are multiple challenges and difficulties for practitioners to find and develop sound methods or tools for capturing the existent knowledge inside the organisations (Sanchez, 2001). While explicit knowledge has been fruitfully exploited (Jamalnia and Feili, 2013; BarYam, 2006; Greasley, 2005; Brailsford and Hilton, 2001), the tacit knowledge existent inside the organisations has not yet been used in dynamic modelling.

The overall aim of this research is to build a dynamic performance measurement system (DPMS) for modeling the key input resources and capabilities to not only evaluate the current manufacturing performance but also to predict future performance. With DPMS, organisations are capable of making fast resource re-deployment decisions and can constantly review the variable inputs that need continuous improvement $(\mathrm{Cl})$. The purpose of this paper is twofold. Firstly, by developing and demonstrating the use of a modelling approach based on cause and effect analysis in real-time to predict future performance and contribute to the existing body of literature (Melnyk et al., 2014; Unahabhokha et al., 2007; Suwingnjo et al., 2000; Bititci, 1996; Neely et al., 1995). The research also fills the gap in knowledge by 
complementing the existing models that use DES and SD using explicit knowledge (Peteraf, 1993; Barney, 1991) through the use of $\mathrm{Cl}$ for identifying the critical variables that can be improved, thus creating a dynamic system. Although such models are complex, once developed they are difficult to copy, thus giving organisations a competitive advantage (Peteraf, 1993; Barney, 1991). The human resources and intellectual property of an organisation are more valuable in combination than separately (Anand et al., 2009). Secondly, to solve a real-world problem by developing a dynamic performance measurement system (DPMS) that models the relationships between a number of key variables driven by operational knowledge (metrics) and tacit knowledge generating production output. Practitioners can model the variables and redeploy their resources to achieve optimum performance. The detailed objectives of this study are:

- To understand the causal relationship between the factors that influence manufacturing output using explicit and tacit knowledge

- To build the DPMS using DES and SD to model the factors that impact manufacturing output

- To test the DPMS and its impact on the organisation.

A UK tyre-manufacturing factory was selected as a case organization in this study for two reasons: Firstly, because planning and scheduling is generally complex in tyre manufacturing (Tabucanon and Petchratanaporn, 1991). Secondly because the tyre industry demand is unpredictable (Sull and Escobari, 2004). In addition, the selected organization was facing performance issues and struggling to identify the root causes of issues in a fast-moving environment while meeting day-to-day needs. The planning lacked dynamism and decisions were taken later after the system's performance has been assessed. There were issues with their resource planning which had a knock-on effect on the production. The main performance measurement system they used was OEE, however in a very reactive approach. Decisions were delayed and issues were escalated to the higher management. There was a genuine need to understand various resources deployment issues that would impact their bottom line 
and proactively manage their production. In order to improve the decision-making process, there was a need for a decision support tool that would help managers deploy the resources in right place at the right time to improve effectiveness and efficiency.

Action research was chosen as the main methodology for achieving the overall aim. The data was collected in five different ways: personal observation; from the shop floor production control and data capturing system (both historic and current); leading and participating in multiple workshops and $\mathrm{Cl}$ events; semi-structured interviews with employees in both formal and informal meetings; and from documents such as meeting minutes, performance measurement white papers and communication documents. Based on the data collected a simulation model was developed, tested and used in the organization to support decisionmaking, and the findings were evaluated. This study used the dynamic capabilities perspective as a means to theorize some of our findings to contribute to the existing literature (Rothaermel, 2013; Crook et al., 2008; Eisenhardt and Martin, 2000; Teece et al., 1997; Wernerfelt, 1995; 1984).

The paper is structured as follows: it starts with the literature review and presents a detailed evaluation on predictive performance measurement. It also reviews the existing literature on Discrete Event Simulation (DES) and System Dynamics (SD) and on hybrid approaches in manufacturing that add dynamic aspects to performance measurement systems. It continues with a section that reviews the dynamic capabilities and the link between the company's tacit and explicit knowledge and the potential development of these dynamic capabilities. This is followed by the presentation of the overall research design, which includes the data collection and analysis. The findings are then presented using the six-stage action research framework implemented in the case organization. The next section presents the findings and finally finishes off with conclusions and further work.

\section{Literature Review}


Performance measurement and management is a mature field with a number of contributions for designing, implementing, using performance measures for decision-making and improvement (Bourne et al., 2000; Bititci, 1996; Neely et al., 1995). However, the majority of the existing models and frameworks were built on measuring only tangible assets/resources and they are static in nature, thus making them less relevant when the strategy changes (Melnyk et al., 2014; Bititci et al., 2012; Franco-Santos et al., 2012; Neely, 2005). Hence understanding the factors influencing performance outcomes in a business or manufacturing environment is crucial for evaluating or predicting performance against their strategy (Bititci and Nudurupati, 2002; Suwingnjo et al., 2000). A few researchers have argued that modelling approaches when used with performance measurement systems will create dynamism in evaluating or predicting performance outcomes (Warren, 2008; Santos et al., 2002; Bititci, 1996).

Hence, in order to achieve the overall aim, it is useful to explore existing literature on predictive performance measurement as well as modelling approaches, and these are presented in the following sections. The most common modelling approaches used in the literature are discrete event simulation (DES), system dynamics (SD), and hybrid approaches, which are discussed here. As the emphasis is on measuring tangible and intangible assets (hence the need to capture both tacit and explicit knowledge), the dynamic capabilities perspective is discussed.

\section{Predictive Performance Measurement}

Time has been described as both a source of competitive advantage and the fundamental measure of manufacturing performance (Stalk, 1998). Other than time, there are multiple factors creating, impacting and transforming the competitive advantage (Porter, 1985). Understanding the sources of competitive advantage has been a constant preoccupation for researchers (Barney, 1991; Porter, 1985; Rumelt, 1984;). Multiple challenges have been raised and some researchers claim that competitive advantage cannot be sustained in dynamic, rapidly changing markets (Einsenhardt and Martin, 2000). However, they 
acknowledge that some companies are more agile, able to change quickly and more willing to change, thus gaining an advantage. Barney et al (2001) suggest that the value of dynamic capabilities must be evaluated in a market context and if the context changes these capabilities will no longer be valuable. Franco-Santos et al (2012) argue that performance measurement systems' effects impact people's behaviour, organisational capabilities and organisational performance in a changing environment. Melnyk et al (2014) highlighted the pace of environmental change as an ongoing issue and performance measurement systems (PMS) were criticised as unreliable in practice for not being sufficiently dynamic. In other words, while strategy changes rapidly, the performance measurement systems were much slower in response, resulting in tension, misunderstood effects and eventually losing their relevance. Hence there is a need for tactical tools to create organisation specific competencies in a changing environment.

Fast decision-making in manufacturing is mainly linked to organisational agility (Yusuf et al., 1999). Agility is defined as "the capability of surviving and prospering in a competitive environment of continuous and unpredictable change by reacting quickly and effectively to changing markets, driven by customer-designed products and services" (Gunasekaran, 2001). However, there are impediments to building an agile, innovative enterprise. An organization may lack sufficient knowledge about itself to know where and when change is needed. Christensen and Overdorf (2000) as well as Winter (2003) have pointed out that important capabilities are often embedded in the less-visible and background processes that support decisions relating to areas such as investment and resource reallocation. Tangible resources tend to depreciate over time (Porter, 1985) so the sole exploitation of those alone may not sustain competitive advantage in long term.

Barr (2014) highlights the need for more research on performance measurement systems including intangible goals and assets. She also calls for people to be engaged in using the measures which affect a company's strategic and tactical levels. Bititci and Nudurupati (2002) 
argue that the closed-loop control system is necessary to continuously monitor the performance of processes to identify and improve the parts of the process. They also argue that performance indicators need to be designed and the relationships need to be modelled in order to sustain continuous improvement (Kaizen) in the outcomes. Suwignjo et al (2000) has explored a number of tools including cognitive mapping, cause and effect diagrams and tree diagrams and developed quantitative models for performance measurement systems to quantify the effect of predictive measures on the top line performance. This work is further extended and enhanced by Sarkis (2003) to incorporate various feedback loops using the analytical network process (ANP) to predict top line performance. Similarly, Tseng (2010) explored a multi-criteria evaluation approach to use balanced scorecard and determine the dependence, analytical network processing, as well as interactive relationships (decisionmaking trial and evaluation). These findings suggest that with the advancement of simulation and modelling techniques, there is a greater opportunity to model the relationships of various resource inputs and capabilities to study their impact on top line performance and throughput.

\section{Discrete event simulation (DES)}

Discrete event simulation (DES) quantitatively represents the real world, simulates its dynamics on an event-by-event basis and generates a detailed performance report (Law and Kelton, 2000). In the early days, DES was used to pre-test flow layouts in fully automated manufacturing systems (Wu and Wysk, 1989) or in a low-volume, mixed model Just-in-Time assembly system (Carlson and Yao, 1992). Welgama and Mills (1995) used a simulation approach to address design problems faced by a chemical organisation, changing from a traditional to a Just-in-Time system, considering alternative designs for the Just-in-Time system. DES is widely used and an increasingly popular method for studying the design and operations of manufacturing systems (Rabelo et al., 2005; Detty and Yingling, 2000; Kleijnen, 1995). In DES, state variables change only at discrete points in time, called 'event times' (Brailsford and Hilton, 2001). 
For DES, accurate historical data is needed to produce statistically relevant results. Exploring the dynamics of the DES, Chong et al (2003) used simulation based scheduling for dynamic discrete manufacturing by using off-line simulation experiments in manufacturing environments that are subject to disturbances based on scheduling approaches. However, DES lacks dynamism and all the reasons for the estimations and causes of correlations cannot be deduced but must be inferred. Moreover, it does not allow the researcher to determine the stability of the system. While DES has long been a popular technique for studying industrial processes, it is also used widely for planning and evaluating design alternatives in a production process (Law and Kelton, 2000; Oakshott, 1997). Wohlgemuth et al (2006) suggests that when simulation models are properly validated, they can be used to answer questions and suggest improvements in complex systems. Exploration of these models can significantly improve the understanding of a modelled system's behaviour.

The difficulties of understanding complex systems are explained by Sterman (2001) as due to the stakeholders failing to understand the full range of feedback operating in the system. In summary the literature notes that DES has a short-term impact (Anand, 2009; Greasley, 2005) and cannot efficiently model complex systems (Rabelo et al., 2005). It is proposed that integration with system dynamics (SD) can generate mid and long-term results (Venkateswaran and Son, 2007).

\section{System Dynamics (SD)}

An increasingly popular simulation method used in production modelling is System Dynamics (SD). SD was developed by Jay Forrester in the mid-1950s to gain a better understanding of the behaviour of complex systems. It is an analytical modelling methodology which combines both qualitative and quantitative aspects (Brailsford and Hilton, 2001). According to Hidaka (1999), SD can be applied in three thinking frameworks: current situation analysis, causal analysis and solution selection. SD assists in strategy development (Sweetser, 1999). It 
captures inputs in causal loops and enables the decision maker to model and compare the performance of a system over a range of alternatives (Sweetser, 1999; Kleijnen, 1995).

Sweetser (1999) suggests that SD is useful to model the system as stocks and various flows in pseudo-continuous time. However, Robinson (2004) suggest that both discrete event modelling and SD can support decision making. While some argue that DES and SD are quite separate simulation approaches (for example, Brailsford and Hilton, 2001), others see them as complementary to one another (Morecroft and Robinson, 2005). SD creates a bridge between long-term strategy and short-term planning (Venkateswaran and Son, 2007). The challenges of quantifying the interactions between input factors were highlighted by Baines et al (2004). They suggest that the gap between actual and predicted performance is due to models failing to incorporate key relationships such as the human impact on performance. There is also an obvious gap between production planning modelling, which operates in discrete time (Diaz-Madronero et al., 2014; Kadar and Monostori, 2001) and factory modelling which operates on a continuous basis (Hidaka, 1999). These findings suggest that there is a need for a more robust integration of DES and SD to fill this gap.

\section{Hybrid approach}

To overcome the difficulties of static modelling, since the early 2000 s there has been a call for reconfigurable manufacturing systems. Mehrabi et al (2002) suggest reconfigurable manufacturing systems as the key to future manufacturing. These systems must be rapidly designed and be able to adapt quickly to changing needs. Hence there is a need to change both discrete and continuous factors in order to be able to respond to disruptions. Santos et al (2002) suggest that the usefulness of the integration SD into the performance measurement systems can be described as a "better identification of the key elements of success".

Hybrid systems are those where discrete and continuous factors co-exist (Größler et al., 2003; 
Huang, 2003; Lee et al., 2002). Qiao et al (2003) proposed a data-driven design and simulation system to support flexible manufacturing. The model can be modified quickly to adjust manufacturing capabilities. Rabelo et al (2005) proposed a hybrid approach to cope with modelling manufacturing systems with increasing complexity. They also emphasize the role of SD in shifting the traditional DES focus from individual decisions to policy structure. In an attempt to create a dynamic model by using only the explicit knowledge existent in the organisation such as robustness, fill rate and inventory level, Sun et al (2012) use multiple simulation models to compare performance. Greasley (2005) attempted to use a DES and SD hybrid approach presenting a case study in a manufacturing environment, highlighting the limitations of a DES in capturing important qualitative data likely to improve the relevance in decision making. In his study, although the usefulness of DES was valuable, the performance of the company was impacted by working practices as well. That study addressed the lack of research in the integration of the tacit knowledge into dynamic modelling as well as their complexity.

Several researchers raised the importance of the possible qualitative issues occurring in making manufacturing decisions (Gregoriades and Karakostas, 2004; Größler et al., 2003; Levin and Levin, 2003). They also stressed the importance for the model to be able to stabilise the processes. Sterman (2001) argues that attempts to stabilise systems may actually destabilise them and Forester calls such a phenomena the "counterintuitive" behaviour of social systems. However with DES and SD approaches, a strong set of criteria is needed for the processes modelled to be sustained and improved (Rabelo et al., 2005). That is mainly because unexpected dynamics often lead to the tendency for interventions to be delayed or defeated (Sterman, 2001). In the vast majority of the organisations, to keep decisions within cognitive bounds, managers must often simplify processes extensively (Russo and Schoemaker, 1989).

\section{Dynamic Capabilities}


Dynamic capabilities define a firm's ability to innovate, adapt to change and improve in a way that is favourable to the customer and unfavourable to their competitors (Teece et al., 2016). Dynamic capability is defined as a "learned and stable pattern of collective activity through which the organization systematically generates and modifies its operating routines in pursuit of improved effectiveness" (Zollo and Winter, 2002, p340). A firm's dynamic capability should govern how it integrates, builds and reconfigures internal and external competences to address changing business environments (Winter, 2003). To manage uncertainty, organisations must have strong dynamic capabilities (Teece et al., 2016).

Winter (2003) argues that an organization's ordinary capability is a high-level routine, or collection of routines that, together with its input flows, confers upon an organization's management a set of decision options for producing significant outputs of a particular type. Teece et al (2016) argue that ordinary capabilities stem from the proficient employment of the firm's human resources, assets (tangible and intangible), processes, and administrative systems, including the coordination needed to combine in-house and external resources. The strength of a firm's ordinary capabilities is a measure of its technical fitness.

Unlike ordinary capabilities, dynamic capabilities are based on developing, carrying and exchanging information through the firm's human capital (Hitt et al., 2001). Dynamic capabilities contrast with ordinary capabilities by being concerned with change. Capturing the tacit knowledge and creativity possessed by the shop-floor people fulfils the $\mathrm{Cl}$ infrastructure function of bottom-up generation of process improvement ideas (Winter, 2003). Anand et al (2009) presented a framework of $\mathrm{Cl}$ infrastructure derived from the dynamic capabilities perspective and its underlying theory of organizational learning (Zollo and Winter, 2002).

Capabilities at an abstract level can be thought of as the ability to co-ordinate activities, learn within an organization, and re-configure resources. Teece et al (1997) have referred to 
learning as a specific type of process underlying dynamic capabilities, which is based on repetition, experimentation and identification of new opportunities. On the other side, dynamic capabilities require a longer-term focus and involve subordinating short-run cost cutting, optimization, and other "best practices" to (longer time) innovation-enhancing strategies. Wernerfelt (1984) argues that it is necessary to view organisations in terms of resources rather than their products to have competitive advantage by creating resource position barriers. $\mathrm{He}$ also calls for more research identifying and developing those niche resources by combining capabilities across different divisions as well as developing structures and systems to implement such strategies for entry barriers. According to Anand et al (2009) process improvement involves organisational learning to make changes in operating routines.

A number of papers discussed the links between capabilities, resources and routines and their contribution to the organization agility and prosperity (Ismail and Mamat, 2012; Gong et al., 2006; Grant, 2003). Many treatments of agility (or flexibility) in the management literature would seem to suggest that firms should persistently seek to become agile no matter the cost, keeping options open all the time, maintaining redundancy at all times, and staying in a constant state of radical transformation (Teece et al., 1997). Due to an increasing pace and complexity of business environments, organisations no longer compete on processes but the ability to continually improve processes (Teece, 2007). Apart from the identification and assessment of the technological opportunities which can successfully be done using DES (Sterman, 2000) there is also a need for the identification and mobilization of relevant resources through the exploitation of tacit knowledge, which can be modelled using SD (Sterman, 2000). Hence there is a need for continued renewal or transformation process facilitated by a continuous improvement framework for superior organisational performance.

It is clear from the literature that DES and SD are increasingly used for dynamic modelling in the manufacturing environment. The literature also demonstrates the usefulness of studying and developing hybrid models. The role of the tacit knowledge in the development of 
competitive advantage as well as in the success of complex dynamic models has been previously emphasised in the literature (Sterman, 2000; Teece, 2007). Only a few studies include tacit knowledge in any of its forms into dynamic models, warranting the need for further study. Therefore, this research uses tacit knowledge in building a dynamic performance measurement system (DPMS) by using a hybrid model to evaluate the current performance and predict the future performance. The emphasis is not in developing another model per se, but the approach for combining performance measurement, modelling techniques and tacit knowledge for applying dynamism to predict future performance. The method used to collect purposive data is crucial in achieving the aim and is discussed in the next section.

\section{Method}

In order to develop and test the dynamic performance measurement system (DPMS) we needed full experimental control in manipulating the input variables to study the impact on OEE (Overall Equipment Effectiveness), planning patterns and production output. The solution was necessary for a real-world problem, which requires personal observation, participation, control and engagement. Hence this study adopted action research as the main strategy in achieving the objectives. Action research involves practical problem solving (with experimental design) which has theoretical relevance (Coughlan and Coghlan, 2002; Mumford, 2001; Gill and Johnson, 1991). The approach aims at both taking action and creating knowledge or theory about that action (Coughlan and Coghlan, 2002). Gill and Johnson (1991) describe action research as a study in which researchers/practitioners, from their interventions and subsequent evaluation not only contribute to the existing knowledge but also solve the practical concerns of the people. In this study, the researchers need to participate and engage in the organizational change simultaneously studying the processes with full access to experimental design and control over the project or context (see Myres, 2009). At the same time, the researchers should also engage in academic activity to identify theoretical significance. 
According to Dyer and Wilkins (1991), single in-depth case studies are richer than shallow multiple case studies. Hence a single action case was selected to spend more time and effort over a two-year period to collect in depth data and highly perseverant analysis (Jarvensivu and Tornroos, 2010). This study took place in a tyre manufacturing facility in the United Kingdom owned by one of the biggest tyre producers in the world.

\section{Case Context}

Tyres are made from a range of rubber and metal components that are combined and transformed in a number of different stages. There are three main stages in the manufacturing process. The initial stage is the preparation stage in which the raw materials (natural rubber) are mixed with various chemicals resulting in uncured rubber compound. All these semifinished products are then transformed in the building stage. The building stage transforms the semi-finished product first into a "carcass" with calendered (heat treated) ply and sidewalls. In the second stage of building, the carcass is transformed to a "green" cover with the metal belts, the tread and the spiral. Finally, at the curing stage the green cover is cured. After quality tests are passed, the finished product is ready to be delivered to the customer. This research looked at the process and the information flow management of the building stage and of the curing stage, which constitute the core areas of the business

The manufacturer's processes were facing severe disruptions. There were significant delays in decision making. Firstly information was escalated hierarchically and most of the times an answer came late. The company also lacked contingency plans in case disruptions occurred. Mainly, decisions were taken based on gut feeling by the team leader or manager and different practices were used on different shifts. For the last 10 years there had been the same patterns of behaviour involving a slow decision process, low productivity with an increased number of orders backlog and unfulfilled orders. The company lacked both strategic and tactical planning. 
Tactically, the production planning lacked a reliable resource allocation in case of disruption which had a knock-on effect on their production. Another important issue was that some of the variables that can affect the throughput, such as waiting times in the process due to work practices or waiting times for managerial decisions, or lack of communication protocols, were barely known to the top management. Strategically, there was a genuine need to understand various input variables (both operational and tacit) that would impact the production throughput. There was a clear need for both a tactical and strategical decision support tool that would help managers with a fast and robust decision making-process they could rely on.

\section{Data Collection}

One of the researchers in this study was based on the company's site every day for two years. The data was collected in five different ways. Firstly, through personal observation and engagement. The researcher was placed in the company for two years to facilitate the change, measure the improvement and study its impact in the organisation. Another researcher visited the organisation once every two weeks to monitor the research project progress throughout this two year study. Secondly, data came from the shop floor production control and from a robust data capturing system (daily, weekly and monthly efficiency and quality reports). For data validation and for testing the model, a number of reports were pulled out from the data systems (both historical and current data). While a majority of the reports were downloaded from the pre-built queries in the system, some reports were obtained through making requests to IT department. Thirdly, data was gained by leading and participating in three workshops and four continuous improvement $(\mathrm{Cl})$ events. These workshops and events were facilitated purposefully to obtain more information for the research project and constituted as a method to capture the initial tacit knowledge from the organisation's members. At these events, data was captured through post-it notes and flip charts, identifying bottlenecks, concerns, ideas and solutions and time and motion studies. Fourthly, data was gathered through 60 semistructured interviews with 28 participants with an overview of their profiles listed in Table 1. Finally data was drawn from documents such as meeting minutes, and performance 
measurement and communication documents. The findings were triangulated to ensure internal validity.

Table 1: Summary of profiles of selected participants in the organisation

\begin{tabular}{|l|c|l|}
\hline Participant job role & Number & Core responsibilities \\
\hline Industrial Director & 1 & Managing the whole plant \\
\hline Mini-Factory Managers & 3 & Daily managing the building, curing and quality plants \\
\hline Efficiency Leaders & 3 & Managing the efficiency metrics and the plant capacity \\
\hline Shift Managers & 5 & Managing a whole shift \\
\hline Shift Coordinators & 5 & Managing manufacturing lines \\
\hline Team Leaders & 7 & Managing manufacturing cells \\
\hline Operational Quality & 2 & Quality checks to comply with customer specs \\
\hline Industrial Quality & 2 & Define the quality procedures in the plant \\
\hline
\end{tabular}

Approach for building Dynamic Performance Measurement System (DPMS)

The data obtained from various sources was triangulated and organised for manual analysis. Observation of data, content analysis and pattern matching were used where appropriate in the study (Yin, 2014). The study was structured on a 6-stage $\mathrm{Cl}$ process action research framework as shown in Figure 1. The first stage consisted of creating project team with members from relevant departments involved in the tyre production process (quality, operations, R\&D, external contractors, senior management, planning). It also included operators and efficiency specialists as well as managers. The second stage involved interviewing and gathering the stakeholders' requirements for identifying performance outcomes to monitor or improve. The third stage consisted of auditing the manufacturing system for gaining a better understanding of the causes and effects as well as a better understanding of the possible noises, and a cycle of continuous improvement $(\mathrm{Cl})$ events was kicked-off. The events, which involved all the relevant people from the shop floor, aimed to understand the complexity of the manufacturing system and to identify all the root causes 
affecting manufacturing performance. Causal loop diagrams were also developed and refined to facilitate the model development and also to predict future performance. The model, with variables and causal relations, was presented at workshops for more insights and crossvalidation.

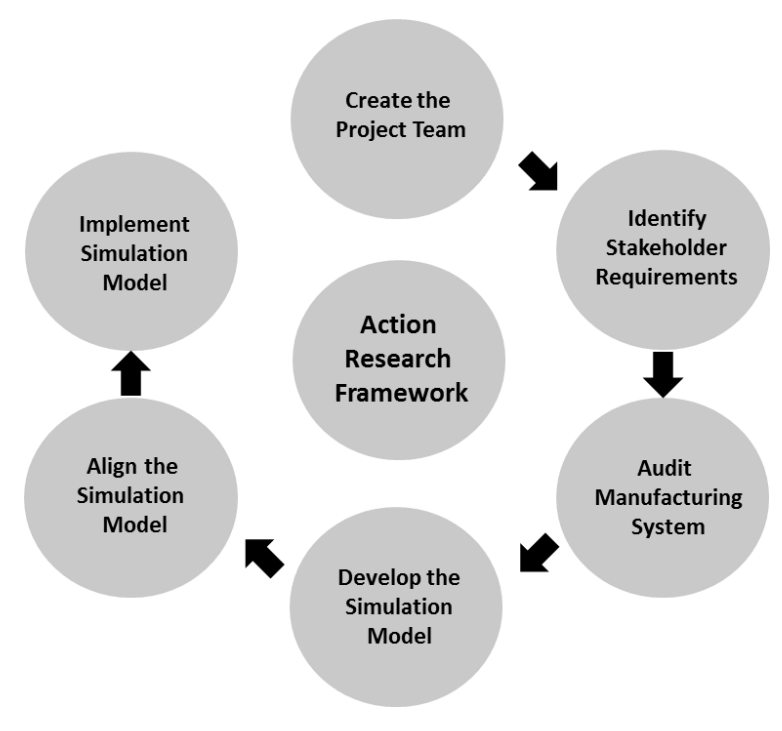

Figure 1: Six-stage research design framework

The fourth stage consisted of developing a simulation model to understand and evaluate the impact of resources and capabilities on the performance outcomes. As a first step, appropriate simulation and modelling software was identified to support the planning decisions identified in the previous stage as shown in Table 2. Sysdea powered by Strategy Dynamics was selected as the best fit for this purpose. A discrete event simulation was designed, developed and implemented which modelled the relationships between OEE (Overall Equipment Effectiveness), production capacity, manning resource, machine resource and production output for this manufacturing system. 


\begin{tabular}{|c|c|c|c|}
\hline Requirement & $\frac{\infty}{\overrightarrow{\underline{E}}}$ & 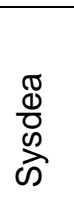 & 禹 \\
\hline $\begin{array}{l}\text { - Ability to create cause and effect analysis of output variables with their } \\
\text { associated input variables }\end{array}$ & & $\checkmark$ & \\
\hline - Ability to see manufacturing performance based on historical data & $\checkmark$ & $\checkmark$ & $\checkmark$ \\
\hline $\begin{array}{l}\text { - Ability to manipulate some of the input variables, i.e. redeploy resources } \\
\text { to see the impact on future performance }\end{array}$ & $\checkmark$ & $\checkmark$ & $\checkmark$ \\
\hline $\begin{array}{l}\text { - Ability to see a visual representation in the form of charts, histograms, } \\
\text { etc., for instance, to see build-up/depletion of inter-stage inventories } \\
\text { while making resource deployment decisions. }\end{array}$ & $\checkmark$ & $\checkmark$ & $\checkmark$ \\
\hline $\begin{array}{l}\text { - Seamless or easier integration of the software with the existing data } \\
\text { sources, i.e. Excel spreadsheets }\end{array}$ & $\nabla$ & $\square$ & $\nabla$ \\
\hline - Tailored price package to suit the usage requirements & & $\checkmark$ & \\
\hline - Continuous support for development of extra tools and capabilities & & $\checkmark$ & \\
\hline $\begin{array}{l}\text { - Ability to develop holistic models built based on sub-models which } \\
\text { simplifies the way data is presented }\end{array}$ & $\checkmark$ & $\checkmark$ & $\checkmark$ \\
\hline - Visibility of the positive and negative feedback loops & & $\checkmark$ & \\
\hline
\end{tabular}

The fifth stage consisted of alignment and the testing of the model to the business needs. The model was validated and revised at the $\mathrm{Cl}$ events in three ways. Firstly, it was internally validated with the supply chain specialists from the company. Secondly it was empirically validated with historical data to verify results against the historical events. Finally, the model was tested with live data to predict results against the forecasts. The sixth stage consisted of the implementation of the model. In this respect, the staff were trained to gather data, to plot and input the data and to interpret results. Moreover, based on the desired output the staff were also trained to re-assign or re-deploy the resources in the simulation model until the desired output was achieved. 


\section{Findings}

The core stakeholders' requirements identified in this study were the following. Firstly, the top management highlighted the low Overall Equipment Effectiveness (OEE) and the struggle to schedule production. Secondly, they stressed the need for a system to help them with effective resource allocation as well as predicting production output. Thirdly, they stressed the importance of a better understanding of a potential link between the input variables, stoppages, manning, methods and production volume that effect performance outcomes. Finally, the shop floor operators, in contrast, raised a concern about the waiting time for making decisions, which caused both frustration and delays and had a domino effect on the production throughput.

The core output factors agreed to be modelled in this case are OEE, inter-stage inventories and production output. After carrying out cause and effect analysis, the research identified the main factors (sometimes called variables, resources and capabilities or operational knowledge) that were affecting the performance outcomes are associated with production losses, both man- and machine-related, manning, and methods used by production operators (tacit knowledge).

The building stage was not synchronised with the curing stage due to complexity and side effects in the processes and the lack of decision visibility. The planning was centralised and every time a disruption occurred in the process, the upstream production stopped and the resources were wasted. Any disruptions or variances in building stage were absorbed by the slack capacity in the curing stage. Carcass inventory accumulated between any of the stages, for example see Figure 2. However, the buffers between $1^{\text {st }}$ stage building, $2^{\text {nd }}$ stage building and curing are seen as critical because these three stages account for the vast majority of the stoppages and production losses thus contributing to the backlog of customer orders. Hence 
these inter-stage inventories needed to be managed to prevent the production stopping because of upstream issues and to decrease the number of backlog orders

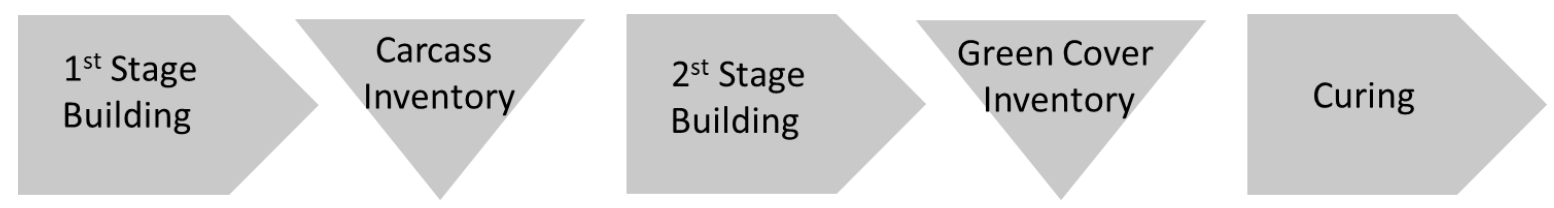

Figure 2 - Manufacturing stages and Inter stage inventory

Downstream planning involved matching the manufacturing capacity of one area (such as building) with the transforming capacity of another (say curing). Often the planners were making decisions based on a trial and error approach due to a lack of tools and techniques available to support their decision-making. The planners deploy the downstream resources arbitrarily by taking a risk margin, which is often between $10-30 \%$. Due to the asynchronous nature of building and curing stages, a lot of resources including people and machines were not deployed appropriately and hence losing efficiency.

The manufacturing process was slow because of multiple waiting times incurred in the decision process. Every time a disruption occurred the planners and the operator waited for a decision on resource redeployment. Moreover, there were 4 different shifts in every area, and some of them were faster than others as their ways of working were different, clearly highlighting the need for process standardisation across the manufacturing facility.

A model of dynamic performance measurement system (DPMS) was built in Sysdea by gathering data on static cause and effect analysis and inputting them into the modelling software to show current manufacturing performance. The aim was to facilitate the management to redeploy the resources and predict the impact on manufacturing performance. The key elements of the model are time, manning, volume, stocks, demand, product range and Kaizen points. The Kaizen points are the variables that can and will be continuously 
improved as part of the model. The system dynamic feedback loops were built based on 'before' and 'after' scenarios highlighting the variables prone to $\mathrm{Cl}$. While the majority of causal links were based on standard formulas defining their relationships, other links were defined using regression. Some relationships between stocks (i.e. man power, inter-stage inventory, availability of workforce, etc.) with other relevant variables were defined based on historical data and experience. However, these relationships are kept to minimum to reduce uncertainty in the overall model fitness.

The model's inputs take into account four aspects: the number of machines running, the speed at which they are running, the number of products that meet the customer's specification, and the number of people deployed to operate these machines as well as the methods used during the processes. Moreover, as soon as a model is created the feedback loop shows the possible side effects on the optimum resource re-deployment. The model also predicts the capacity of the tyre production line and is tailored for different types of machines. Because cycle time differs with every machine type, a different sub-model is needed for each line, with a bigger model integrating them all. Some of the variables feeding the availability and the productivity have a direct impact on the number of tyres built. The basic assumption of the model is that a machine builds at its maximum capacity providing there are no stoppages and it operates on a full shift with all comfort breaks covered and with no stoppages or other speed losses. However, during the operating time of the machine, there are both foreseeable and unforeseeable stoppages. The foreseeable stoppages are the ones occurring on a regular basis such as: planned absence, preventive maintenance, industrialisation, operators' rest, change overs, routine operations, etc. The other stoppage types are subject to unpredictability and include breakdowns, quality issues, waiting for material, etc. While predictable variables have a constant value (or slightly fluctuating within control limits to incorporate natural variation), the unpredictable variables were given random values in the model following a normal distribution curve (an assumption suggested by Hussin and Hashim, 2011). These variables can be continuously improved, becoming Kaizen Points. 
The model was evolved on a number of iterations based on historical data across a wide range of processes leading to different products. This not only improved the simulation model accuracy but also highlighted the reasons behind the current manufacturing performance. The model evaluated alternative supply chain designs for optimisation of resource allocation based on decisions suggested by a simulation/modelling approach. The model was also tested with historical data to quantify and visually demonstrate how the resource allocation. Figure 3 represents the main causal loop used in building the DES. The balancing loop operates when a problem is identified in the manufacturing process, thus putting the customer order into backlog, which eventually becomes an unfulfilled order. The unfulfilled orders have an impact in slowing the manufacturing process, demanding flexible decisions to be made in order to fulfil the backlog orders with priority. This delay has a negative impact on the productivity and it builds the carcass stock. The increase of the carcass inventory put pressure on the curing process which needs to consume these carcasses. By not consuming the carcasses it delays the orders, adding orders in the backlog. The reinforcement loop highlights the actions that produce the decrease in building carcasses and increase in cured carcasses, thus releasing curing capacity (the manufacturing bottleneck). 


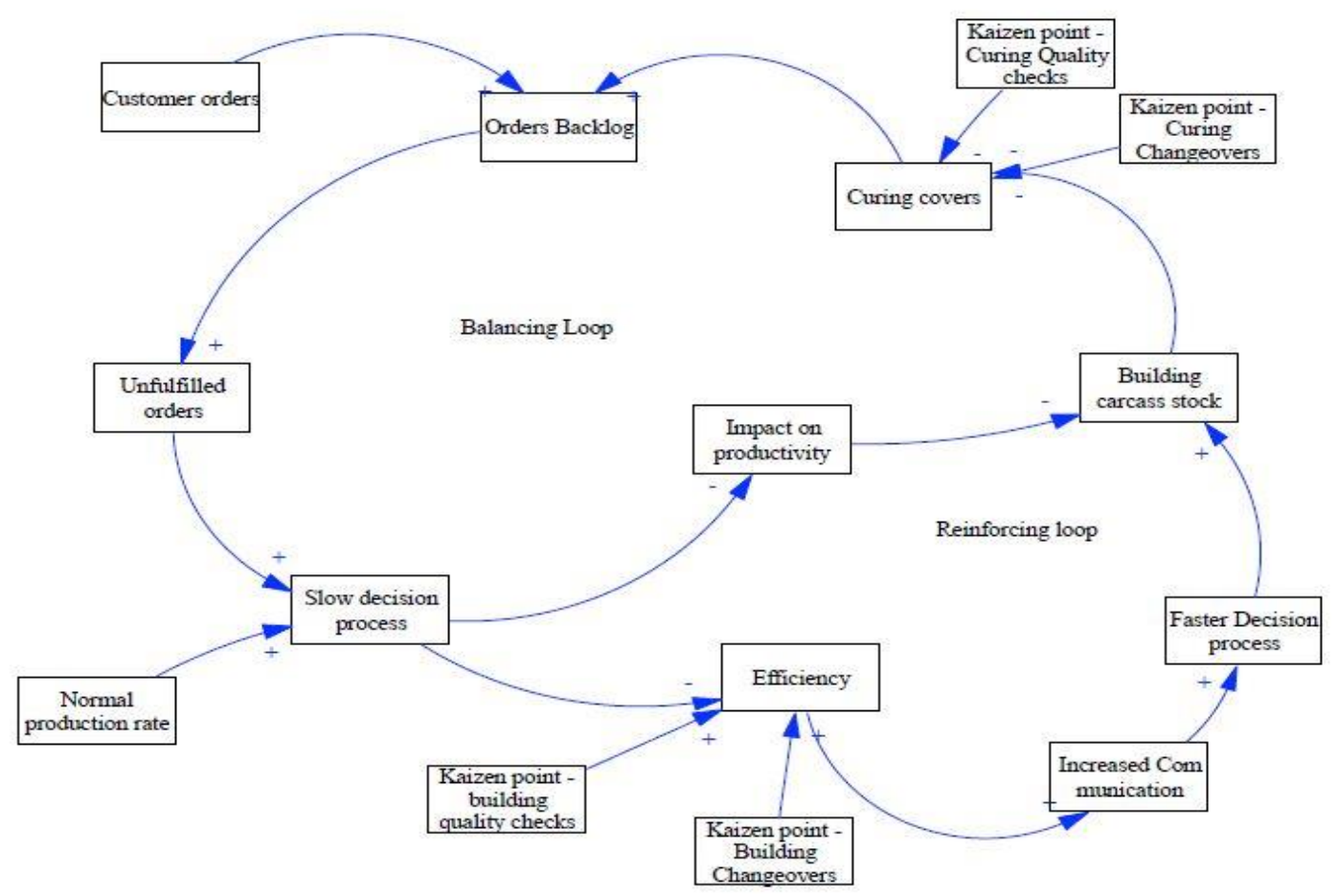

Figure 3: The main causal loop diagram of the model

The model was tested and validated in three phases on a tyre production line. In the first phase, a pilot manufacturing process was chosen and historical data was plotted into the model. The project team checked the accuracy of the model and the eventual inconsistencies against the factual data. With minor tweaks the modelled scenario approached the scenario from past real-life events. In the second phase the team gathered field (real-time) data and plotted it into the model, analysing the response of the model in respect to the resources allocated as well as the inter-stage inventory and their effect on manufacturing performance. The model was tested for two weeks and the data was recorded on a daily basis. Apart from the stoppages and all other explicit data, the number of people assigned to the building machines was recorded as well as the impact of the methods used during the process. In other words, it recorded the total amount of time spent on the building machine. Next, the observed data values in the real-life are manually inputted in the simulation model software, and compared against the predicted values from the system. Once again the modelled scenario approached the real-life scenario. 
In the third phase, with support from the researchers, the senior managers used the model in their decision-making and re-allocated the resources based on the model suggestions to verify improvements in the manufacturing performance. That is, if the predicted production output was lower than the desired output, the capacities and resources were increased or redeployed in building and/or curing stages. This phase not only tested the accuracy and usefulness of the model but also built senior management confidence in the model, which increased other stakeholders' interest in the model. The most important finding in this stage showed that by using the DPMS the company became more agile by reducing its decision times, increasing its flexibility in planning and becoming faster in re-deploying resources in case of disruptions.

The model is open, dynamic and real-time and some input variables (Kaizen Points) are included in the company's Cl strategy. These features gave strength and sustainability to the model enabling the company to focus on the improvement of the manufacturing processes. The $\mathrm{Cl}$ method gave the company the opportunity to bring in the dormant tacit knowledge and exploit it.

\section{Results}

The case company is operating in a dynamic and complex manufacturing environment with challenges from a multitude of variables that could affect manufacturing or production performance. Without a DPMS, the decision process was extremely slow as in case of disruptions, the team leader's or manager's decisions were needed. In addition, the production planners were deploying downstream resources arbitrarily using their gut feeling and by taking risk and following trial and error approach. Downstream planning involved matching the manufacturing capacity of one mini-factory with the transforming capacity of another. 
The development of DPMS helps the management in their decision-making process of resource allocation and in predicting the optimum resource allocation and the performance of the internal supply chain. The DPMS dynamically models a multi echelon, multi-product system with periodic ordering and evaluates alternative resource allocation with respect to the system's maximum capacity. Production planners are now using the DPMS in making informed decisions, which also empowered them and shortened the decision-making process. By entering all the information on input measures (such as manning, machine availability, breakdowns, etc.) the planners are able to predict manufacturing performance (OEE, interstage inventories, production output, labour utilisation, etc.) more accurately. It gives them power to run what-if scenarios to see its impact on performance and redeploy (change, increase or decrease) resources until the desired outcome is reached before actually implementing changes in live production.

The building and the curing operators are focusing on the Kaizen points (changeovers and quality checks) following newly established standard operating procedures. These Kaizen points are constantly reviewed (every 6 months) and re-adjusted for the model to constantly reflect the company's operating routines.

The DPMS offers both the benefit of holistic planning of the production and the opportunity to individually model production lines separately in order to have a quantifiable impact on the whole. Hence it has both a strategic as well as tactical planning usability. In the presented model it is used for the scenario based-approach in which the variables are generated statistically using data on either forecast stoppage percentages or normally distributed data where machine stoppages occur. The assumption is that breakdowns or quality issues occur following a normal distribution curve. The Kaizen points are the operating routines that can be improved and constantly reviewed. These variables represent the operators' ways of working (changeovers, quality checks, waiting times, information flows) and represent the tacit 
knowledge inside the organisation. In addition to problem solving, the Kaizen points promote the learning of individuals through the interaction and the interpretation of a given situation.

The DPMS was used in Kaizen events and other $\mathrm{Cl}$ projects in different ways. Firstly, it enabled some of the action plans to be modelled to see any potential improvement before implementing these actions (sensing). Secondly it enabled the improvement teams to define the Kaizen points and see whether the input variables are operating between the limits UCL and LCL (3sd from the mean) to verify whether the processes are stable (diagnosing). Finally by reducing the decision-making time (team leaders and planners avoided escalation), it increased the agility in planning and it increased the agility in optimum resource deployment in case of disruptions (reconfiguring).

The model was used by the team leaders for optimum resource allocation for achieving the number of acceptable units required by the customer. When there were changes in planned resources, the model suggested resource re-allocation and contributed to strategic decisions on resource re-deployment in order to achieve the planned performance. In addition, the model was used to see how the inventory is likely to accumulate or deplete in a defined time period based on their existing plans and number of sizes in production. This helped planners when redeploying resources to keep inventory in the optimum limits.

The method used in designing and implementing the model through $\mathrm{Cl}$ cycles helped the researchers and the company to identify which processes can be constantly adjusted and streamlined (quality checks and changeovers) transforming the operating routines into dynamic capabilities. These processes are used in the model as critical variables or Kaizen points. Prior to using DPMS, decisions were always made by senior management based on their gut feeling (intuition) and deployed to lower levels. People on the shop floor who were involved with production on a day-to-day basis had little input into planning decisions. As demonstrated in Figure $4 a$ and $4 b$, with the use of DPMS, the central and bureaucratic 
decision-making has evolved into local, informed and empowered decision-making. The middle management and supervisors on the shop floor were able to make planning decisions locally based on the information provided by the model. This resulted in a cultural shift driving improvement projects.

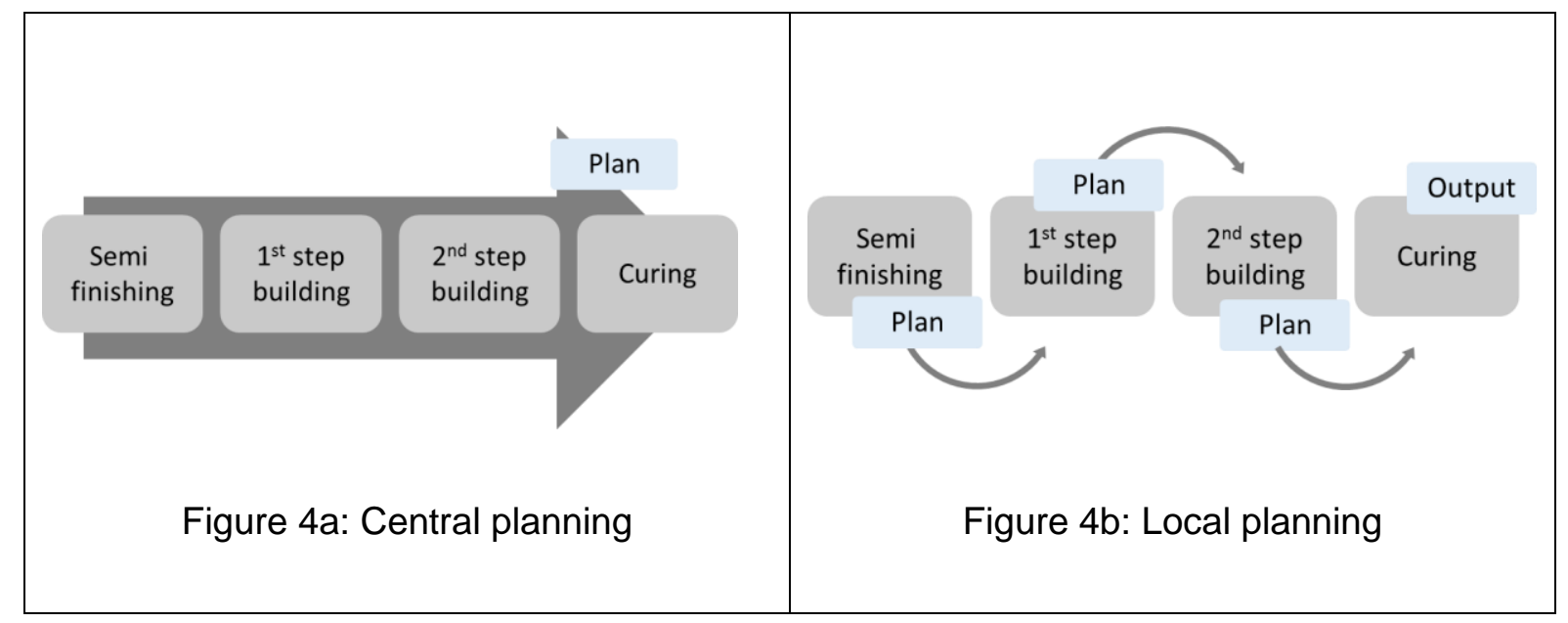

\section{Discussion and management implications}

The lack of clarification of relationship between the widespread resources in the manufacturing process and their impact on performance outcomes is amongst the main reasons why manufacturers are far away from developing efficient manufacturing systems (Soloukdar, 2012). Moreover, the failure to capture all relevant feedbacks in a complex system is one of the main causes of failure in modelling complex systems (Sterman, 2000). These concerns can be impediments in building agile and fast decision-making systems. Moreover, it also prevents the company developing a competitive advantage against the competitors (Teece et al., 1997, Rothaermel, 2013). Hence researchers call for a dynamic model, which can cover all relevant aspects (i.e. inputs, outputs, inter-stage inventory, manning resources) (Teece et al., 2016; Christensen and Overdorf, 2000; Winter, 2003).

Cause and effect analysis has been a popular method for building many $\mathrm{Cl}$ projects. While it is a common tool used to understand complex systems, it is a static representation of 
relationships between inputs and outputs. The significant development in this paper is to take these static relationships and make them more dynamic by quantifying the relationships, modelling them using both the explicit and tacit knowledge existent in the business and creating a $\mathrm{Cl}$ framework. While the need for a dynamic performance measurement systems (DPMS) was identified in literature (Melnyk et al., 2014; Bititci et al., 2012; Franco-Santos et al., 2012; Neely, 2005; Bititci and Nudurupati, 2002; Suwingnjo et al., 2000), the drive to develop such system was obtained from modelling approaches (Warren 2008; Santos et al., 2002; Bititci, 1996).

Silver (1991) suggest that quantitative models are useful for decision making if they represent the problem realistically and permit some of the 'usual givens' to be treated as decision variables. Although using output measures such as OEE as well as the effects of inputs and their dependence is not entirely new (see Tseng, 2010; Sarkis, 2003; Suwignjo et al., 2000) few studies explored, tested and validated the input factors and their impact on OEE and production output in a real and dynamic manufacturing environment using DES and SD. Hence the emphasis of this research is in developing a visual and intuitive approach (as demonstrated in Figure 3) for deploying manufacturing resources and inventory policies in an effective and efficient manner to influence and predict performance. The explicit and tacit knowledge used in the development of this dynamic model in which the cause and effect relationships are clearly defined is likely to give a dynamic capability to the organisation (Esterby-Smith et al., 2009) which can be transformed into a temporary competitive advantage to the organisation that implements it (Rothaermel, 2013; Barney, 1991).

The proposed DPMS model is a hybrid between DES and SD to model forecasted data to give projections for future planning. The hybrid model overcomes some of the concerns raised by researchers with regards to the limitations of the DES and SD used in isolation (SD cannot map batch production and lacks accuracy in modelling while DES in isolation does not suggest feedback loops) (Jovanoski et al., 2013). In order to sustain the simulation model, a Cl 
framework is proposed, which is a robust method for capturing the existent tacit knowledge. In addition, the model and $\mathrm{Cl}$ framework incorporates sensing (identify changes and opportunities), diagnosing (develop new ways of responding to changes) and reconfiguring (reorganise existent operating routines) capabilities (Gonzalez \& Martins, 2016).

The originality of the DPMS model comes from the approach used to build the cause and effect analysis by exploiting the tacit knowledge and making it dynamic by adding modelling capabilities. The DPMS can capture variables, named Kaizen points, which can be improved through Kaizen events with shop floor teams participating in the continuous analysis and development of the input variables. The risk of not capturing important but not so obvious variables in complex manufacturing systems is also mitigated. Moreover, the operational routines are continuously adjusted and enhanced regularly for sustaining superior performance (Helfat et al., 2007; Teece, 2007; Winter, 2003).

The new capability was organised in such a way for the company to capture its value. The relevant input variables were identified as $\mathrm{Cl}$ variables thus offering the company valuable tools for continually enhancing those processes. By highlighting the potential of some of the manufacturing stages the model created common expectations, behaviours, and goals hence it enabled the changes in capacity and the ability to reduce cycle time of all activities.

Decision making in planning the design and operations of manufacturing processes is often based on several factors, of which some of them are uncertain. In this action research, uncertainties arose in capacities or constraints of manning or machine resource allocation, conditions such as breakdowns, potential quality issues and optimum inventory levels. On top of all these explicit and quantifiable variables there are variables influenced by the operators ways of working which sometimes can heavily influence the manufacturing throughput. All these uncertainties affect the performance of the manufacturing system, including its service 
levels and delivery lead-times, which in turn affect the business competitive environment (Liu et al., 2004).

The current research brought some practical implications. Firstly, it brought value by capturing key tacit and explicit resources, their dependence on performance as well as a tool for optimum deployment. Secondly, it brought a rare intangible resource, a blend of DES and SD developed through employing a $\mathrm{Cl}$ technique covering all the relevant dynamic aspects of manufacturing. Thirdly, through the development of the $\mathrm{Cl}$ method it created a dynamic capability, which encompasses both the strategic and tactical views of company. Finally, the model was embedded in the organisational culture through $\mathrm{Cl}$ processes organised to continuously capture value. In essence, an organisation can model their dynamic capability to enable them to gain competitive advantage in a constantly changing environment.

The model can also help practitioners to categorise the losses as chronic and sporadic as suggested by Jonsson and Lesshammar (1999), define kaizen points and stabilise and improve losses which are normally governed by uncertainty. The current research mitigated the uncertainty risk by organizing Kaizen Events to control some of the input variables, which varied historically exceeding the upper control limits (UCLs) or the lower control limits (LCLs). The method is preferred to the main alternative Design of Experiments (DOE) due to time and cost constraints (Kleijnen, 1995). Moreover, the tactical tool is aimed to be used shift by shift whereas DOE or ANOVA might be too difficult to be used by the operational staff.

\section{Conclusion}

The DPMS acted as a predictive measurement system and supported the implementation of manufacturing strategy by controlling input variables such as resource allocation, disruptions, inventory, changeovers, etc. (Nudurupati et al., 2011; Suwignjo et al., 2000). It also inputs explicit variables built on existing data as well as critical variables (Kaizen points) that can be 
improved over time. Controlling the critical variables is highly likely to control uncertainty and disruption. Hence, the measurement system not only works as passive control, but is also used as $\mathrm{Cl}$ (Jonsson \& Lesshamar, 1999). The model has strong momentum for initiating $\mathrm{Cl}$ projects as it highlights such opportunities.

The paper has presented a DPMS which has modelled multi-stage production, with multiple machine families with different behaviours. The model has demonstrated its usefulness in exploring and controlling the predictable and some of the unpredictable variables in the manufacturing system by suggesting a day-to-day resource allocation. The use of visual and predictive aspects of DPMS has transformed the company's central and bureaucratic decision-making into local, informed and empowered decision-making. In the broad context, this paper contributes to operations management literature by demonstrating in practice that a dynamic performance measurement system (DPMS) can be created by combining performance measurement models with modelling approaches. As Melnyk et al (2014) highlighted, when the strategy changes in the organisation, the model needs to be revised by updating new output measures and input measures in the light of new strategy. Through this research the use of static relationships in cause and effect analysis is enhanced to dynamic relationships to evaluate and predict performance in a new way, thus contributing to $\mathrm{Cl}$ and performance measurement literature (Suwignjo et al., 2000; Sarkis, 2003; Tseng, 2010).

In practice, the DPMS enabled the company's tangible (explicit) and intangible (tacit) resources to transform into dynamic capabilities (manufacturing flexibility and agile resource re- deployment), which are likely to create competitive advantage. The DPMS is a tool that can be used to understand, manage and enhance the manufacturing performance through the following capabilities: Sensing to observe changes and opportunities and initiate $\mathrm{Cl}$ initiatives; Diagnosing to identify the problems, route causes, stabilise and to improve uncertain processes; and finally Reconfiguring to redeploy resources and routines and enhance the dynamics of the model. 
Despite the fact that the model developed in the current research is specific and unique to this organisation, the approach (i.e. the way DPMS was developed by defining Kaizen points and by building it through multiple $\mathrm{Cl}$ cycles) is transferrable to other batch production make-toorder manufacturing businesses where the benefits will be replicated. The case has also demonstrated the positive impact the DPMS had on the organisation's decision-making process and on increasing agility in planning and predicting outcomes at both strategic and tactical levels.

Although the findings were based on one action case, the authors are confident that the findings are generalizable to other similar manufacturing companies due to the analytical nature of the solution presented (Yin, 2014). The important element of the DPMS is its accuracy of prediction, which depends on the ability to define relationships between different variables, i.e., while most of the relationships are derived by using formulas (which are accurate and reliable), some have to be defined based on correlation and regression (where the accuracy could fall down). If the manufacturing environment has more of these uncertain relationships then it will affect the accuracy of DPMS and hence its suitability will be limited. Hence in future more of these studies should be performed in different manufacturing settings such as fast moving consumer goods (FMCG), make-to-stock or high-shelf life inventories under various settings to extend and strengthen this research. It is also necessary that future researchers should focus more on objectives methods such as DES and SD, particularly on hybrid approaches when predicting business performance. Objective methods such as multicriteria decision analysis (MCDA) could be used with SD in enhancing the effectiveness of selecting measures during design and implementation PMS while taking input from various stakeholders (Santos et al., 2002). These analytical approaches limit subjectivity, ambiguity and conflict between measures thus improving the effectiveness of measuring and managing performance. Further studies are also required to expand the scope of evaluating and 
predicting manufacturing performance to the full business, taking other aspects into consideration. 


\section{References}

Ahmed, S., and Sahinidis, N.V. (1998), "Robust Process Planning under Uncertainty", Industrial \& Engineering Chemistry Research, Vol. 37, pp. 1883-1892

Anand, G., Ward, P., Tatikonda, M. (2009), "Role of explicit and tacit knowledge in Six Sigma projects: An empirical examination of differential project success", Journal of Operations Management, Vol. 28, pp. 303-315

Baines, T., Mason, S., Siebers, P. and Ladbrook, J. (2004), "Humans: The missing link in manufacturing simulation?", Simulation Modeling Practice and Theory, Vol. 12, pp. $521-526$

Barney, J. (1991), "Firm Resources and Sustained Competitive Advantage", Journal of Management, Vol. 17, No.1, pp. 99-120

Barney, J.B., Wright, M. and Ketchen, D. Jr. (2001), "The resource-based view of the firm: ten years after 1991", Journal of Management, Vol. 27, No. 6, pp. 1601-1621

Bar-Yam, Y. (2006), "Improving the Effectiveness of Healthcare and Public Health: A Multiscale Complex System Analysis", American Journal of Public Health, Vol. 96, No. 3, pp.459- 466

Barr, S. (2014), Practical Performance Measurement: Using the PuMP Blueprint for Fast, Easy, and Engaging KPIs, The Pump Press.

Bititci, U. (1996), "Modelling Performance Measurement Systems in Manufacturing Enterprises", International Journal of Production Economics, Vol. 42, No. 2, pp. 137147.

Bititci, U. and Nudurupati, S.S. (2002), "Using performance measurement to drive continuous improvement”, Manufacturing Engineer, Vol. 81, No. 5, pp. 230-235

Bititci, U., Garengo, P. Dörfler, V. and Nudurupati, S. (2012), "Performance measurement: challenges for tomorrow", International Journal of Management Reviews, Vol. 14, No. 3, pp. 305-327. 
Bourne, M., Mills, J., Wilcox, M., Neely, A., and Platts, K. (2000), "Designing, implementing and updating performance measurement systems", International Journal of Operations and Production Management, Vol. 20, No. 7, pp. 754-771.

Brailsford, S. and Hilton, N., (2001), "A comparison of Discrete Event Simulation and System Dynamics for Modelling Healthcare System", Proceedings of the $26^{\text {th }}$ meeting of the ORAHS Working Group, Glasgow, Scotland.

Carlson, J.G. and Yao, A.C. (1992), "Mixed-model assembly simulation”, International Journal of Production Economics, Vol. 26, pp.161-167

Chong, C.S., Sivakumar, A.I. and Gay, R. (2003), "Simulation-Based Scheduling for dynamic Discrete Manufacturing, Proceedings of the 2003 Winter Simulation Conference, New Orleans, USA, pp. 1465-1473

Chopra, S. and Meindl, P. (2007), Supply Chain Management: Strategy, Planning and Operation, $6^{\text {th }}$ ed., Pearson, New York.

Christensen, C.M. and Overdorf, M. (2000), "Meeting the challenge of disruptive change", Harvard Business Review, Vol. 78, No. 2, pp 66-76.

Coughlan, P. and Coghlan, D. (2002), "Action research for operations management", International Journal of Operations \& Production Management, Vol. 22, No. 2, pp.220 $-240$

Crook, T.R., Ketchen, D., Combs, J.G. and Todd, S. (2008), "Strategic Resources and Performance: A Meta-Analysis", Strategic Management Journal, Vol. 29, pp. 11411154

Detty, R.B. and Yingling, J.C. (2010), "Quantifying benefits of conversion to lean manufacturing with discrete event simulation: A case study", International Journal of Production Research, Vol. 38, No. 2, pp. 429-445

Díaz-Madroñero, M., Mula, J. and Peidro, D. (2014), "A review of discrete-time optimization models for tactical production planning", International Journal of Production Research, Vol. 52, No. 17, pp. 5171-5205 
Dyer, W.G. Jr. and Wilkins, A.L. (1991), "Better Stories, Not Better Constructs, to Generate Better Theory: A Rejoinder to Eisenhardt", Academy of Management Review, Vol. 16, No. 3, pp. $613-619$

Eisenhardt, K.M. and Martin, J.A (2000), "Dynamic Capabilities: What are they?", Strategic Management Journal, Vol 21, pp. 1105-1121

Esterby-Smith, M., Lyes, M.A. and Peteraf, M., (2009), "Dynamic Capabilities: Current debates and future directions", British Journal of Management, Vol. 20, pp. S1-S8

Franco-Santos, M., Lucianetti, M. and Bourne, M. (2012), "Contemporary performance measurement systems: A review of their consequences and a framework for research", Management Accounting Research, Vol. 23, No. 2, pp. 79-19

Gill, J. and Johnson, P., (1991), Research Methods for Managers, Paul Chapman Publishing, London

Gong, Q., Wang S., Lai K.K. (2009), "Stochastic analysis of TPS: expose and eliminate variability by highly specific WCP", International Journal of Production Research, Vol.47, No.3, pp. 751-775

Gonzalez R.V.D. and Martins M.F. (2016), "Capability for continuous improvement: Analysis of companies from automotive and capital goods industries", The TQM Journal, Vol. 28 No. 2, pp. $250-274$

Grant, R.M. (2003), "Strategic planning in a Turbulent Environment: evidence form the oil and gas majors", Strategic Management Journal, Vol. 24, pp. 491-518

Greasley, A. (2005), "Using system dynamics in a discrete-event simulation study of a manufacturing plant", International Journal of Operations and Production Management, Vol 25, No.6, pp. 534-548

Gregoriades, A. and Karakostas, B. (2004), "Unifying business objects and system dynamics as a paradigm for developing decision support systems", Decision Support Systems, Vol. 37, No. 2, pp.307-311

Größler, A., Stotz, M., and Schieritz, N. (2003), "A software interface between system dynamics and agent-based simulations: linking Vensim® and RePast®”. Proceedings 
of the 21st System Dynamics Society International Conference, New York, NY, 20-24 July.

Gunasekaran, A. (2001), Agile Manufacturing: The $21^{\text {st }}$ Century Competitive Strategy, 1 st ed., Elsevier.

Harrington, L., Kennerly, D. and Johnson, C. (2011), "Safety issues related to the electronic medical record (EMR): Synthesis of the literature from the last decade, 2000-2009", Journal of Healthcare Management, Vol. 56, No. 1, pp. 31-44.

Harrison A. and Van Hoek R. (2011), Logistics Management and Strategy, Prentice Hall, FT.

Helfat, C.E., Finklestein, W., Mitchell, W., Peteraf, M., Teece, D. and Winter, S. (2007), Dynamic Capabilites: Understanding Strategic Change in Organizations, Blackwell, London.

Hidaka, S., (1999), "System Dynamics: a New Tool for TQM", 17th International System Dynamics Conference

Hitt, M.A., Bierman, L., Shimzu, K., Kochar, R. (2001), "Direct and moderating effects of human capital on strategy and performance in professional service firms: A resourcebased perspective", Academy of Management Journal, Vol. 44, No. 1, pp.13-28

Huang, G.Q., Lau, S.K.J. and Mak, K.L., (2003), "The impacts of sharing production information on supply chain dynamics: A review of the literature", International Journal of Production Research, Vol. 41, No. 7, pp 1483-1517

Hussin, H. and Hashim, F.M. (2011), "Modeling of Maintenance Downtime Distribution using Expert Opinion", Journal of Applied Sciences, Vol. 11, pp.1573-1579

Ismail, A. and Mamat, M. (2012), "The relationship between information technology, process innovation and organizational performance", International Journal of Business and Social Sciences, Vol. 3, No. 2, pp. 268-274.

Jamalnia, A. and Feili, A. (2013), "A simulation testing and analysis of aggregate production planning strategies", Production Planning \& Control, Vol. 24, No. 6, pp. 423 - 448 
Järvensivu, T. and Törnroos, J. (2010), "Case study research with moderate constructionism: Conceptualization and practical illustration", Industrial Marketing Management, Vol. 39. No. 1, pp.100-108.

Jeong, K.Y. and Phillips, D.T. (2001), "Operational efficiency and effectiveness measurement", International Journal of Operations \& Production Management, Vol. 21, No.11, pp. 1404-1416

Jonsson, P. and Lesshammar, M. (1999), "Evaluation and improvement of manufacturing performance measurement systems - the role of OEE", International Journal of Operations and Production Management, Vol. 19, No. 1, pp. $55-78$

Jovanoski, B., Minovski, R.N., Lichtenegger, G., Voessner, S. (2013), "Managing strategy and production through hybrid simulation", Industrial Management \& Data Systems, Vol. 113, No. 8, pp. 1110-1132.

Kadar, B. and Monostori, L. (2001), "Adaptive Agents in Distributed Manufacturing Systems, IFAC Proceedings, Vol. 34, pp. 87-92

Kleijnen, J.P.K. (1995), "Verification and validation of simulation models", European Journal of Operational Research, Vol. 82, pp.145-162

Law, A.M. and Kelton, W.D. (2000), Simulation Modeling and analysis, McGraw-Hill

Lee, Y.H., Cho, M.K., Kim, S.J., Kim, Y.B. (2002), "Supply chain simulation with discretecontinuous combined modelling", Computer and Industrial Engineering, Vol. 43, 375392

Levin, T., \& Levin, I., (2003), "Integrating hybrid modeling with system dynamics. 21st International Conference", System Dynamics Society, July 20-24, New York, USA

Liu, L., Liu, X., and Yao, D.D. (2004), "Analysis and Optimization of a Multistage InventoryQueue System", Management Science, Vol. 50, pp. 365-380.

Mehrabi, M.G., Ulsoy, A.G., Koren, Y. and Heytler, P., (2002), "Trends and perspectives in flexible and reconfigurable manufacturing systems", Journal of Intelligent Manufacturing, Vol. 13, pp. 135-146 
Melnyk, S., Bititci, U., Platts, K., Tobias, J. and Andersen, B., (2014), "Is performance measurement and management fit for the future?", Management Accounting Research, Vol. 25, No. 2, pp 173-186.

Morecroft, J.D.W. and Robinson, S. (2005). "Explaining puzzling dynamics: comparing the use of system dynamics and discrete-event simulation", Proceedings of the 23rd International Conference of the System Dynamics Society, System Dynamics Society, Boston, MA

Mumford, E., (2001), "Advice for an action researcher", Information Technology \& People, Vol. 14, No.1, pp.12- 27

Myres, M., (2009), Qualitative Research in Business and Management, Sage, London.

Neely, A. D., Mills, J. F., Gregory, M. J. and Platts, K. W. (1995), "Performance measurement system design - a literature review and research agenda", International Journal of Operations \& Production Management, Vol. 15, No. 4, pp 80 - 116.

Negahban, A. and Smith, J.S. (2014) "Simulation for manufacturing system design and operation: Literature review and analysis", Journal of Manufacturing Systems, Vol. 33, No. 2, pp. 241-261

Nudurupati, S.S., Bititci, U.S., Kumar, V. and Chan, F.T.S. (2011). "State of the art literature review on performance measurement", Computers \& Industrial Engineering, Vol. 60, pp. 279-290.

Oakshott, L. (1997), Business modelling and simulation, Pitman.

Peteraf, M.A. (1993), "The Cornerstones of Competitive Advantage: A resource based View", Strategic Management Journal, Vol. 14, No. 3. pp. 179-191

Porter, M.E. (1985), Competitive Advantage, The Free Press, New York.

Qiao, G., Riddick, F. and McLean, C.R. (2003), "New manufacturing modeling methodology: data driven design and simulation based on XML, Proceedings of the $35^{\text {th }}$ winter simulation conference, New Orleans, USA 
Rabelo, L., Helal, M., Jones, A., Min, H-S. (2005), "Enterprise simulation: a hybrid system approach", International Journal of Computer Integrated Manufacturing, Vol. 18, No. 6, pp. $498-508$

Robinson, S., (2004), Simulation: the practice of model development and use, Chichester: Wiley.

Rothaermel, F.T., (2013), Strategic Management: concepts and cases, McGraw-Hill/Irwin, New York.

Rumelt, R.P. (1984), "Towards a strategic theory of the firm”. In R. Lamb (ed.) Competitive Strategic Management, Prentice-Hall, Englewood Cliffs, NJ, pp. 556-570

Russo, J.E. and Schoemaker, P.J.H. (1989), "Decision Traps: Ten barriers to brilliant decisionmaking and how to overcome them, $1^{\text {st }}$ ed., Simon \& Schuster.

Sanchez, R. (2001), Modularity, Strategic Flexibility and Knowledge Management, Oxford University Press.

Santos, S.P., Belton, V. and Howick, S. (2002), "Adding value to performance measurement by using system dynamics and multicriteria analysis", International Journal of Operations \& Production Management, Vol. 22, No. 11, pp.1246-1272

Sarkis J., (2003), "A strategic decision framework for green supply chain management", Journal of Cleaner Production, Vol. 11, pp. 397-409

Silver, E.A. (1991), "Modelling in support of continuous improvements towards achieving world class operations". In: Sarin, R.K. (Ed.), Perspectives in Operations Management. Kluwer Academic Publishers, Dordrecht.

Silver, E.A., Pyke, D.F., and Peterson, R. (1998), Inventory Management and Production Planning and Scheduling, $3^{\text {rd }}$ ed., New York: John Wiley \& Son.

Silvestro, R. and Lustrato, P. (2014), "Integrating financial and physical supply chains: the role of banks in enabling supply chain integration", International Journal of Operations \& Production Management, Vol. 34, No. 3, pp. 298-324 
Soloukdar, A., (2012), "Designing and analysis a Dynamic Model of World Class Manufacturing in Iranian automotive industry", The $30^{\text {th }}$ International conference of System Dynamics Society.

Sterman, J.D. (2000), Business Dynamics: Systems Thinking and modelling for a Complex World, McGraw-Hill, New York.

Sterman, J.D. (2001), "System Dynamics Modelling: Tools for learning in a complex world", California Management Review, Vol. 43, No. 4, pp.8-25

Sull, D.N. and Escobari, M. (2004), "Creating value in an unpredictable world", Business Strategy Review, Vol.15, No.3, pp.14-20

Sun, Y., Hart, J.D. and Genton, M.G. (2012), 'Nonparametric inference for periodic sequences', Technometrics, Vol. 54, 83-96.

Suwingnjo, P., Bitici, U., Carrie, A.P. (2000), "Quantitative Models for Performance Measurement System", International Journal of Production Economics, Vol. 64, No.13, pp. 231-241

Sweetser, A. (1999), "A Comparison of System Dynamics and Discrete Event Simulation" Proceedings of 17th International Conference of the System Dynamics Society and 5th Australian \& New Zealand Systems Conference, Wellington, New Zealand.

Tan, K.H. and Platts, K.W. (2005), "Effective Strategic Action Planning: A Process and Tool", International Journal of Business Process Management, Vol 11, No. 2, pp. 137-157

Tan, K.H. and Platts, K.W. (2009), "Linking operations objectives to actions: a plug and play approach", International Journal of Production Economics, Vol. 121, No. 2, pp. 610619

Teece, D.J., Pisano, G. and Shuen, A. (1997), "Dynamic capabilities and strategic management", Strategic Management Journal, Vol. 18, No. 7, pp. 509-533

Teece, D.J., Peteraf, M., Leih, S. (2016), "Dynamic Capabilities and Organisation Agility: Risk, Uncertainty and Strategy in the Innovation Economy, California Management Review, Vol. 58, No.4, pp. 13-35 
Tabucanon, M.T. and Petchratanaporn, S. (1991), "Tyre Manufacturing: Simplifying a Complex Production Planning and Scheduling Problem", Logistics Information Management, Vol. 4, No. 3, pp.10 - 14

Tseng, S.M. (2010), "The correlation between organizational culture and knowledge conversion on corporate performance", Journal of Knowledge Management, Vol. 14 No. 2, pp. 269 - 284

Unahabhokha, C. Platts, K. and Kim, H.T., (2007), "Predictive performance measurement system: A fuzzy expert system approach", Benchmarking: An International Journal, Vol. 14, No. 1, pp. 77 - 91

Venkateswaran, J. and Son, Y.J. (2007), "Effect of information update frequency on the stability of production-inventory control systems", International Journal of Production Economics, Vol. 106, pp. 171-190

Waters, C.D.J. (1992), Inventory Control and Management, John Wiley \& Sons, Chichester Welgama, P.S. and Mills, R.G.J. (1995), "Use of simulation in the design of JIT system", International Journal of Operations and Production Management, Vol. 15, pp. 245-260

Wernerfelt, B. (1984), "The Resource-Based View of the Firm", Strategic Management Journal, Vol. 5, No. 2, pp. 171-180.

Wernerfelt, B. (1995). "The Resource-Based View of the Firm: Ten Years After", Strategic Management Journal, Vol. 16, No. 3, pp. 171-174

Winter, S.G. (2003), "Understanding dynamic capabilities", Strategic Management Journal, Vol. 24, No. 10, pp.991-995

Wohlgemuth, V., Page, B., Kreutzer, W., (2006), "Combining discrete event simulation and material flow analysis in a component-based approach to industrial environmental protection", Environmental Modelling \& Software, Vol. 21, No. 11, pp. 1607-1617

Wu, D.S. and Wysk, R. A. (1989), "An Application of Discrete-Event Simulation to On-Line Control and Scheduling in Flexible Manufacturing", International Journal of Production Research, Vol. 27, pp. 1603-1624. 
Yin, R. K. (2014), Case Study Research: Design and Methods. 5th ed., Thousand Oaks, CA: Sage.

Yusuf, Y.Y., Sarhadib, M. and Gunasekaran A. (1999), "Agile manufacturing: the drivers, concepts and attributes, International Journal of Production Economics, Vol. 62, No. 1-2, pp. 33-43

Zollo, M. and Winter, S. G. (2002), "Deliberate learning and the evolution of dynamic capabilities", Organization Science, Vol. 13, 339-351 